\title{
Differenz
}

Revista internacional de estudios heideggerianos y sus derivas contemporáneas

AÑO 8, NÚMERO 7: JULIO DE 2021. ISSN 2695-9011 - e-ISSN 2386-4877 - DOI: 10.12795/Differenz.2021.i07.01 [pp. 11-24]

Recibido: 03/09/2020

Aceptado: 10/03/2021

\section{Uma contribuição de Chuang-tzu ao pensamento de Heidegger: o cultivo do inútil.}

\section{Chuang-tzu's contribution to Heidegger's thought: the cultivation of the useless.}

Óscar Federico Bauchwitz

Universidade Federal do Rio Grande do Norte

Resumo:

O interesse de Heidegger pelo pensamento asiático é algo reconhecido pelos intérpretes da sua obra. $\mathrm{O}$ que se procura expor aqui é uma parte desse interesse, analisando e contextualizando a presença do Chuang-tzu onde Heidegger o traz à colação com o propósito de interpretar o sentido do inútil. Para Heidegger, o inútil designa a especificidade e o caráter próprio da filosofia e do pensamento meditativo, ao tempo que permite pensar a liberdade e a disposição humanas desde uma perspectiva não utilitarista do mundo técnico. Em Chuang-tzu, Heidegger encontrou um interlocutor privilegiado, valendo-se de suas parábolas para pensar em outro modo de realização do habitar humano que exige a necessidade de apresentar e fomentar o cultivo do inútil.

Palavras-chave: Chuang-Tzu; Heidegger; Inútil; Meio-ambiente. 


\section{Abstract:}

Heidegger's interest in Asian thought is something recognized by the interpreters of his work. What is sought to be exposed here is part of that interest, analysing and contextualizing the presence of Chuang-tzu where Heidegger brings it to the collation with the purpose of interpreting the meaning of the useless. For Heidegger, the useless designates the specificity and character of philosophy and meditative thinking, while allowing human freedom and disposition to be thought from a non-utilitarian perspective of the technical world. In Chuang-tzu, Heidegger found a privileged interlocutor, using his parables to think of another way of realizing human habitation that requires the need to present and promote the cultivation of the useless.

Keywords: Chuang-tzu; Heidegger; Useless; Environment.

Há tempos que a relação entre Heidegger e o Oriente fomenta inúmeras interpretações com perspectivas e objetivos diversos que parecem preparar um caminho ou, ao menos, nos aproximar daquilo que Heidegger chamou de o "incontornável diálogo com o mundo asiático oriental" ${ }^{1}$. Não se procura aqui expor uma abordagem exaustiva do interesse que Heidegger cultivava pelo pensamento oriental ${ }^{2}$. Como adverte o nosso título, trata-se de considerar uma pequena parte desse interesse, analisando a contribuição de Chuang-tzu ao pensamento de Heidegger e ao que este chegou a pensar sobre o sentido do inútil. 0 que se procura é investigar o lugar conquistado pelo chinês no pensamento heideggeriano, quer dizer, de que modo se explicita a recepção de Chuang-tzu por parte de Heidegger?

1 Citamos, primeiramente, a edição alemã das obras de Heidegger e, a continuação a tradução utilizada. HeIdegGer, M. "Wissenschaft und Besinnung" In Vorträge und Aufsätze. GA 7. Klostermann, Frankfurt an Main, 2000, p.41/ "Ciencia y Meditación" in Conferencias y artículos. Odós, Barcelona, 1994, p.41.

2 A obra heideggeriana guarda algumas citações e poucas linhas sobre o taoísmo. Faz referências ao Tao Te Ching ou Dao De Jing e se dispôs a traduzi-lo com a colaboração de Paul Shih-yi Hsiao (19111986); também ao "pensamento poético" de Lao-Tsé na perspectiva de uma linguagem despojada do ente; ao Chuang-tzu e suas parábolas. Mas, não deixa de ser oportuno recordar que em Princípio de Identidade (1957) no qual anuncia a palavra-guia de seu pensamento, gestada ao longo das últimas décadas, Heidegger advirta que "o Ereignis é de tão difícil tradução quanto o logos e o Tao". Tal interesse foi e continua sendo objeto de análise dos estudiosos, não só respeito a Chuangtzu mas também às confluências entre o pensador e o taoísmo. Outros exemplos do interesse de Heidegger pelo asiático é a relação com o Japão e o impacto de Ser e Tempo, o diálogo "De um conversa sobre a linguagem entre um japonês e um pensador" de A Caminho da Linguagem (Unterwegs zur sprache) e em inúmeras relações pessoais e docentes que manteve, bem como a recepção por parte da Escola de Kyoto. Para uma introdução ao tema: MAY, R. Heidegger's hidden sources - East asian influences on his work. Routledge, London-New York, 1996; SAVIANI, Carlo. EI Oriente de Heidegger. Herder, Barcelona, 2004. 
Que questões suscita a experiência do inútil para que Chuang-tzu contribua para a sua reflexão e, especialmente, de que modo em tal experiência se decide o destino do ser humano e do mundo que habita e constrói?

Heidegger menciona, ao menos, em quatro ocasiões o Chuang-tzu³: a primeira, em 1930, narrada por Petzet, quando Heidegger lê o capítulo 17 -A alegria dos peixes ${ }^{4}$; a segunda, no Conversa ao entardecer entre um mais novo e um mais velho em um campo de prisioneiros na Rússia, em 1945, citando, sem explicitar a sua origem, parte do capítulo 26; a terceira, na ementa do Seminário Imagem e Palavra (Bild und Wort) ministrado em Bremen em 1960, onde se indica a leitura do capitulo 19 -O campanário e, finalmente, na conferência Língua de tradição e língua técnica, em 1962, onde cita o capítulo 1 -A árvore inútil. Analisaremos primeiro o diálogo de 1945 e a conferência de 1962 procurando expor o contexto de onde emergem as questões que acabam por preparar um lugar para os ensinamentos de Chuang-tzu; em seguida, procura-se confrontar as escolhas de 1930 e 1960 com o que foi alcançado na análise anterior.

Na compreensão cotidiana, nos diversos afazeres que nos ocupam, algo é considerado inútil quando não possui utilidade, ou bem porque a perdeu (um martelo quebrado, por exemplo), ou então porque respeito a determinada situação não oferece a serventia requerida (um martelo frente a tarefa de extrair uma rolha de uma garrafa de vinho!). O inútil é, pois, à primeira vista e de modo explícito, não ser capaz de ser útil, o nãoútil, o não necessário, o que não encontra serventia. O inútil é, em suma, segundo essa compreensão, algo que não serve para nada. Por essa compreensão, perguntar pelo sentido do inútil pode soar tão estranho que uma vez formulada a pergunta, a sua resposta parece tão óbvia que pode parecer "coisas de filósofo" perder tempo em respondê-la, um

3 A obra de Chuang-tzu ou Zhuang zi possui inúmeras edições e traduções em línguas ocidentais. Dada a complexidade e a composição da obra, com interpolações e autorias diversas, poucas são as edições que respeitam a sua extensão na totalidade e que procuram se aproximar do idioma original. Por outra parte, para facilitar ou tornar mais atraente a leitura, algumas edições incluem títulos ou subtítulos já consolidados pela tradição da recepção ocidental, embora ausentes no original chinês. As referências e citações seguem, com a nossa tradução ao português, a edição espanhola de Iñaki Preciado Ydoeta, Zhuang zi-"Maestro Chuang Tsé" (Kairós, Barcelona, 1996) que segue a de Chen Guying, Zhuang zi jin zhu jin yi (O Zhuang zi com notas e tradução modernas), Shangwu, Taibei, 1977.

4 Petzet conta que em 1930, em Bremen, após ter apresentado a conferência Da essência da verdade (Vom Wesen der Wahrheit), na recepção que se organizara em sua homenagem, Heidegger se dirige ao seu anfitrião e Ihe pede a edição do Chuang-tzu: "O silêncio geral lhe fez temer ter sido inoportuno, considerando o tipo de relações entre os bremenses: pedir um livro desconhecido e por a Kellner (o anfitrião) em um compromisso (...) Este, no entanto, não duvidou (...) em poucos minutos voltou com a edição de Buber do Chuang-tzu". PeTZET, H.W. Encuentros y diálogos con Martin Heidegger 1929-1976 (Tr. Lorenzo Langbehn). Katz, Buenos Aires, 2007. 
despropósito que não colabora em nada com o atual estado de coisas que cotidianamente se impõem como prementes.

Colocar a questão do sentido do inútil, no entanto, não justifica -o mais provável é que desautorize- aqueles que criticam e buscam impedir o ensino da filosofia por causa de sua incapacidade de apresentar efeitos imediatos que pudessem minimizar a premência coercitiva do mundo e, em consequência, por não inspirar confiança em alcançar os resultados esperados de um processo educativo. A questão do inútil é uma questão que envolve o próprio sentido da Filosofia.

Em Introdução à Metafísica, Heidegger, longe de defender a Filosofia desse caráter inútil, procura legitimá-lo:

a filosofia tampouco consiste em um saber que se possa aprender imediatamente, como os conhecimentos artesanais e técnicos, ou que se possa aplicar imediatamente, como os conhecimentos econômicos ou professionais em geral, contabilizando em cada caso sua utilidade (Nutzbarkeit). Mas, o inútil (Nutzlos), no entanto e precisamente por sê-lo, pode constituir um poder. Aquilo que não conhece a ressonância imediata na realidade cotidiana pode encontrar-se na mais íntima harmonia com o acontecer autêntico de um povo dentro de sua história ${ }^{5}$.

Estamos diante de algo que, propriamente, demarca a filosofia dos demais saberes. Não só não pode ser submetida e avaliada pelos mesmos parâmetros de mensuração que determinam a utilidade, como também, de modo espantoso, reivindica a sua aproximação ao inútil. Aquilo que a filosofia considera não pertence ao domínio do útil, as suas questões demandam uma espera e um aprender a esperar que não se move pelas demandas oriundas daquele domínio. Pensar que a filosofia por não atender ao domínio do útil deve ser banida é, para Heidegger, tão espirituoso (geistreich) quanto considerar que como não se pode voar com um banco de carpinteiro, então teríamos que nos desfazer dele 6 . Por outro lado, Heidegger entende que fazer frente a essa incompreensão sobre o sentido da Filosofia, saindo em defesa da sua utilidade, pode acabar promovendo outra incompreensão tão ou ainda mais errônea quanta à que a declara inútil; tal seria o caso de homologar a sua utilidade porque seria capaz de apresentar uma visão de mundo que pudesse orientar e facilitar a existência humana. Essas duas incompreensões e as suas consequências, por um lado, o banimento da Filosofia e, por outro, a tentativa de justificá-

5 HeIDegger, M. Einfhrung in die Metaphysik. Klostermann, Frankfurt an Main, 1983, s.10/ Introducción a la Metafísica. Tr. A. Ackerman. Gedisa, Barcelona, 2001, p.18 .

6 lb. s. $12 /$ p. 19. 
la por servir aos propósitos de uma sociedade, não só pertencem e se originam a partir do domínio do útil, como também impedem pensar o que é propriamente a Filosofia. Que se admita que a Filosofia é inútil, que com ela nada pode ser feito, não encerra a questão, antes poderíamos suspeitar de ser o caso de se inverter tal questão diz Heidegger. Ao invés de perguntar o que podemos fazer com a Filosofia, não deveríamos nos perguntar se ela pode fazer algo conosco? ${ }^{7}$

Até aqui o sentido do inútil pouco se mostrou, salvo por negar-se a ser útil. Como sabemos o que é o útil, entendemos o inútil como a sua negação. Mas, podemos nos perguntar: é possível pensar o inútil sem apelar ao útil? Não será que no acontecimento da experiência da utilidade e da serventia se oculta um sentido a partir do qual o próprio útil seja como é e, em consequência, desvendando tal sentido, se descobriria algo de próprio respeito ao não-útil? Ao parecer, somente nos aproximamos do sentido do inútil quando o próprio útil torna-se claro para nós.

Em Ser e Tempo, Heidegger evidencia que o ente que sou e como a gente é, o ser-aí (Dasein), encontra-se já e sempre em meio a uma compreensão do mundo, no mais das vezes regida pelo autoritário impessoal, que determina as suas possibilidades existenciais e a sua relação com aqueles entes que não possuem o seu modo de ser. Nesta relação se abre e se decide o destino do mundo como algo que está em suas mãos concretizar. Incapaz de pôr-se a si mesmo diante da morte, o ser-aí quer assegurar-se, tanto quanto lhe seja possível, que o porvir seja um resultado esperado, calculado e desejado. Ocupandose de consolidar o seu mundo, o ser-aí se assegura de que efetivamente se realize como esperado. Ser útil é servir a um fim esperado, pertencer e mostrar-se como útil em meio ao mundo circundante. No ser-útil a existência humana afiança o seu estar no mundo, a tal ponto que diante de um instrumento incapaz de atender as suas necessidades, sente surpresa pela importunidade e percebe o caráter de manualidade de seu mundo.

Vejamos agora a primeira das referências escritas que Heidegger faz do Chuangtzu, presente em Conversa ao entardecer entre um mais novo e um mais velho em um campo de prisioneiros na Rússia. O pano de fundo deste diálogo é a própria guerra que tocava a seu fim e traz uma reflexão acerca do mundo contemporâneo, caracterizado pela emergência planetária do útil (Notigen). Heidegger lembra uma estória do Chuang-tzu, Uma conversa entre dois pensadores:

Um diz: tu falas sobre o inútil (Unnötige).

7 Ib. s. 14/p. 21. 
O outro diz: Uma pessoa deve primeiro reconhecer o inútil antes de falar do útil. A terra é vasta e ampla, e ainda assim, para ficar em pé o homem somente precisa do espaço suficiente para colocar seus pés. Mas, se tudo que estiver em torno aos seus pés caísse dentro de uma fenda até o fundo mais subterrâneo, então o lugar onde o homem se mantém em pé ainda teria alguma utilidade?

Um diz: não teria nenhuma utilidade.

O Outro diz: isso mostra claramente a necessidade do inútil ${ }^{8}$.

Heidegger conclui a redação do diálogo no dia 08 de maio de 1945, "no dia em que o mundo celebrou sua vitória e ainda não reconheceu que há séculos já está vencido pela sua própria revolta"9. A datação do fim da guerra, em que pesem o significado e os funestos resultados obtidos, no entanto, não permite identificar a desolação (Verwüstung) tratada pelo diálogo com um determinado e trágico período de alguns anos; a guerra mundial é consequência de uma desolação que há séculos devasta a terra. Vejamos uma passagem do diálogo:

O mais jovem: A desolação também domina, justamente e, sobretudo, nas terras e povos não alcançados pelas destruições da Guerra.

O mais velho: onde o mundo surge no brilho da prosperidade, das vantagens e das bonanças, onde se respeitam os direitos humanos, onde a ordem burguesa se mantém e onde, sobretudo, se asseguram meios e veículos para a constante satisfação de um bem estar indestrutível de maneira a tudo calcular e instituir como útil ${ }^{10}$.

Desolação significa "que o mundo, o homem, a terra estão se transformando em deserto (Wüste)"11. Um deserto que não indica uma ausência absoluta de possibilidades mas, de um estranho modo, a desolação indica a presença de uma possibilidade e só. A lei desse deserto é a lei da desolação: "o necessário tornar-se o mais útil e o único necessário"12. Exposta à necessidade dessa lei, a existência humana se encontra em uma procura constante de afiançamento e arrazoamento da realidade, uma ansiedade

8 HEIDEGGER, M. "Abendgespräch in einem Kriegsgefangenenlager in Russland zwischen einem Jüngeren und einem Älteren". In Feldweg-Spräche 1944/1945. Klostermann, Franfurt an Main, 1995. s. 239.

9 Ib. s. 240.

10 lb. s. 216.

11 lb. s. 236.

12 Id. 
e uma cobiça determinadas pelo apelo apaziguador do útil e pela dolorosa interdição do caminho para o inútil: "A dor ardente é não podermos nos fazer presença para o inútil"13.

A estória de Chuang-tzu conclui uma conversa cujo cenário está determinado pela desolação. A sabedoria taoísta parece capaz de propiciar ao pensamento uma experiência salutar, evidenciando o único ensinamento manifestamente assumido no diálogo heideggeriano: "a precariedade e a necessidade do inútil"14. Se a desolação torna o homem cego para o inútil, ela o faz porque no âmbito das demandas que regem o seu mundo, não pode haver lugar para o inútil, como tampouco se outorgará lugar para o pensamento. $O$ pensamento é inútil desde que não se lance ao cálculo e ao planejamento do mundo e ao controle da natureza; é inútil desde que não aporte luz à realidade, não colabore na sua fundamentação; é inútil se ele se pautar pelo respeito à inviolabilidade do possível. A inutilidade do pensamento, no entanto, é algo negativo ou privativo respeito ao locupleto caráter do mundo da técnica moderna, que mais tarde denominará de Gestell (armação ou composição). Não é inútil por falta, mas por excesso de premência. Para além da perspectiva do mundo técnico, o pensamento se mostra inútil porque é essencialmente livre. A inutilidade mostra-se, então, como uma elevada qualidade e possibilidade essencial do ser humano, porque ela expressa algo que é realmente próprio do pensamento, a outorga e a habitação da liberdade. O inútil é o que não se limita à premência do útil.

A experiência do inútil é a experiência de não sentir falta disso ou daquilo com o propósito de atender a uma necessidade. No domínio do inútil, o necessário é a liberdade, o deixar ser livre. Lemos: "é conseguindo deixar algo entregue à sua própria essência que estamos verdadeiramente livres. A liberdade está em poder deixar e não ordenar e controlar"15. Este "deixar ser" algo em sua própria essência demanda a insistência em uma espera que não se orienta pelos resultados, "algo que seja palpável, que pudesse ter alguma utilidade para o progresso, para o aumento das curvas de produtividade e para o elegante curso dos negócios"16. O "deixar ser" permanece à espera, e é propriamente estar à espera do Livre. $O$ inútil é o verdadeiramente necessário porque acolhe a liberdade e promove a experiência de ser um "mestre da pobreza", como escreve Heidegger em uma possível deferência a Mestre Eckhart tal como faz, por exemplo, em $A$ coisa, $A$ volta, Serenidade, entre outros.

13 lb. s. 219.

14 lb. s. 237.

15 Ib. s. 230.

16 Ib. s. 234. 
Em A pobreza, texto concluído umas poucas semanas depois de Conversa ao entardecer..., Heidegger interpreta um fragmento de Hölderlin -"Entre nós, tudo se concentra sobe o espiritual, nos tornamos pobres para chegar a ser ricos"17- e acaba por considerar que a sentença do poeta com seu caráter de oximoro deixa ver algo de fundamental acerca do que é o necessário e do que é o não-necessário. Para Heidegger,

ser-pobre quer dizer: não carecer de nada, salvo do não-necessário (Unnötige) (...) ser-pobre é carecer unicamente do não-necessário, isto é, pertencer alguma vez ao Livre-Liberador, quer dizer, manter-se em relação com o Liberador ${ }^{18}$.

O necessário é o que provém da necessidade premente, coercitiva, que, no mais das vezes, empenha o agir do homem para a sua satisfação. O não-necessário, que nestas considerações determina a pobreza-riqueza, ao contrário, não provém da necessidade premente senão que provém do Livre, do resguardado, o que se subtrai a toda utilidade. O que provém do Livre, diz Heidegger, é preservado e deixado em sua essência, é liberado de toda e qualquer coerção. O que há de liberador na liberdade transforma a própria necessidade premente. A necessidade se mostra, contra toda a tradição metafísica, a própria experiência de liberdade: "só a liberdade é em si a Necessidade convertida (Notwendigkeit)"19. Com a Necessidade convertida desvela-se o ser-pobre na relação com o Livre, o homem torna-se pobre em sentido próprio e, ao mesmo tempo, torna-se rico:

Pelo fato mesmo de que a pobreza não nos faz carecer de nada, temos de entrada tudo, nos mantemos na superabundância do Ser (Überfluss des Seyns), que desborda por antecipado todo o necessitante do necessário ${ }^{20}$.

Embora sendo a mais próxima e essencial, a experiência da pobreza não é, de modo algum, familiar. Heidegger observa que o perigo da escassez e dos tempos indigentes impede que a pobreza seja experimentada essencialmente. O perigo da fome, por exemplo, uma realidade à época da conferência, não era o fato de que as pessoas chegassem a morrer de fome, senão que o perigo mais extremo era que os sobreviventes só vivessem para comer. Ser-pobre somente é possível na medida em que, seguindo a palavra do poeta, "tudo se concentre sobre o espiritual".

17 Para um esclarecimento da sentença de Hölderlin, veja-se a apresentação de Lacoue-Labarthe à edição francesa de Die Armut, presente também na edição em espanhol: HEIDEGGER, M. La pobreza. Amorrortu, Buenos Aires-Madrid, 2006, pp. 23 ss..

18 HeIDEgGER, M. "Die Armut". In Zum Ereignis-Denken. GA 73-1. Klostermann, Frankfurt an Main, 2013, s. 879/La pobreza, cit., p. 111-112.

19 lb. s. 878/p. 109.

20 lb. s. 880/p. 115. 
A outra referência do Chuang-tzu acerca do inútil escrita e analisada por Heidegger se encontra em Língua de tradição e língua técnica (1962). Heidegger aborda o caráter dual do pensamento e da linguagem que correspondem, por um lado, ao cálculo, ao planejamento, enquadramento e arrazoamento característico do domínio imposto ao mundo pela técnica moderna e, por outro lado, a capacidade humana de pensar meditativamente. Como indica o seu título, o texto procura pensar acerca da língua, da técnica e da tradição, expondo uma meditação (Besinnung) sempre arriscada. Tal risco provém do próprio ato de meditar. Escreve Heidegger:

meditar significa despertar o sentido para o inútil. Num mundo para o qual não vale senão o imediatamente útil e que não procura mais que o crescimento das necessidades e do consumo, uma referência ao inútil fala sem dúvida, num primeiro momento, no vazio. (...) Que deve e que pode ainda o inútil face à preponderância do utilizável? ${ }^{21}$

A concepção do inútil engendra um questionamento e uma reflexão inabituais. Assim como no diálogo acima mencionado (Conversa ao entardecer...), aqui também se faz uso da tradição oriental, com a estória de Chuang-tzu acerca da "árvore inútil", para evidenciar a dificuldade de se pensar o inútil. Heidegger cita a estória do Chuang-tzu na íntegra:

Hui-tzu dirigiu-se a Chuang-tzu e disse: "Eu tenho uma grande árvore. As pessoas chamam-lhe a árvore dos deuses. O seu tronco é tão nodoso e disforme que não se pode cortar a direito. Os seus ramos são tão torcidos e tortos que se não podem trabalhar com peso e medida. Está à beira do caminho, mas nenhum marceneiro a olha. Assim são as vossas palavras, senhor, e todos se afastam de vós ao mesmo tempo". Chuang-tzu respondeu: "Haveis visto uma marta que se põe à espreita com o corpo encolhido e que espera que qualquer coisa aconteça? Ela vai e vem correndo sobre as traves e não se impede de dar saltos elevados até que um belo dia, cai numa armadilha onde perece por um laço. E depois há também oyak. É grande como uma nuvem de tempestade; eleva-se no seu poder. Mas não pode apanhar os ratos. Da mesma maneira vós tendes uma grande árvore e lamentais que não sirva para nada. Porque não a plantais numa terra deserta ou num campo vazio? Aí poderíeis passear na sua proximidade ou dormir à vontade sobre os seus ramos sem nada fazer. O machado e nenhuma outra coisa lhe reservam um fim prematuro e ninguém lhe pode

21 HeIDEgGer, M. Überlieferte Sprache und technische Sprache. Erker, St. Gallen, 1989, p. 6-7/ Língua de Tradição e língua técnica, Tr. M. Botas. Passagens, Mafra, 1995, p.9. 
fazer mal. Como é bom que nos preocupemos com uma coisa que não tem utilidade!"22.

Avesso a toda medida, deve-se descobrir a grandeza própria do inútil e reconhecer o seu modo de ser. $\mathrm{O}$ inútil revela-se como algo com o qual não necessitamos nos ocupar. $\mathrm{O}$ intangível e o durável também são pela inutilidade (Nutzlosigkeit) e seria um contrassenso aplicar ao inútil a medida da utilidade. O inútil diz Heidegger tem um poder determinante: "com ele nada se pode fazer. É desta maneira que é inútil o sentido das coisas"23. Nesse sentido, a meditação proposta por Heidegger em nada contribui com a organização prática do ensino, mas planteia a possibilidade de que a descoberta de uma nova perspectiva acerca do inútil venha a abrir "um horizonte que determine constantemente e em todos os lugares o conjunto das reflexões sobre a prática pedagógica, mesmo que não seja o nosso centro de atenção"24. Mas, o que podemos esperar do inútil se com ele nada se pode fazer? Heidegger explica que quando meditamos, aquelas representações correntes que guiam e determinam a relação para com aquilo que é a técnica, a língua e a tradição, sofrem uma metamorfose no pensamento, tornando-se dignas de serem pensadas e, portanto, questionadas.

Heidegger também indica a existência de dois textos semelhantes do Chuang-tzu. Não explicita a que textos se refere, mas, ao menos duas parábolas do mesmo capítulo que antecedem imediatamente o texto escolhido por Heidegger, trazem exemplos que podem ilustrar o sentido do inútil. A primeira se refere à parábola de Hui-tzu que havia sido presenteado com uma semente de cabaça gigante que uma vez plantada frutificou e mostrou-se inútil para armazenar líquidos ou servir de recipiente por causa de seu tamanho e peso. Para Chuang-tzu, o fato de ser inútil para o uso que se desejava, não implicava necessariamente na sua destruição; Hui-tzu poderia ter-Ihe amarrado algumas cordas e fazer dela um tipo de balsa que lhe permitiria navegar por lagos e rios ${ }^{25}$. A segunda parábola é usada como exemplo para explicar a primeira, quer dizer, para evidenciar que o útil e o inútil não podem ser determinados de modo antecipado e definitivo, senão que correspondem à necessidade de determinadas circunstâncias. É o caso de um unguento criado por um lavador de seda que Ihe protegia as mãos em sua jornada de trabalho. Ao ter notícias desse produto, um forasteiro pagou algumas moedas ao lavador e se fez com a fórmula. Por sua vez, o forasteiro apresenta ao rei o unguento como solução para proteger

22 lb. Veja-se ChUANG-Tzu. Op. cit., pp. 40-41.

23 Ib. s. 8/p. 12.

$24 \mathrm{lb}$. Lembremos que o texto foi proferido para um público formado por professores de escolas profissionais.

25 Chuang-Tzu. Op. cit., pp. 39-40. 
as mãos dos soldados das intempéries, logrando que os mesmos pudessem disparar suas flechas com mais intensidade do que os seus inimigos, alcançando, assim, a vitória em combate. O rei agradecido concedeu um feudo ao forasteiro. Assim, diz Chuang-tzu, o mesmo unguento serviu a um para adquirir um feudo e a outro para lavar a seda, o que se entende pelos diferentes usos que dele se fez ${ }^{26}$. À primeira vista, as três parábolas evidenciam que o útil se descobre segundo a necessidade que a cada vez se manifesta. Mas, os ensinamentos de Chuang-tzu não se limitam a distinguir ou descobrir uma utilidade ou outra. Como vimos, não se trata apenas da descoberta da impropriedade de um certo útil, por exemplo, do martelo frente a uma garrafa de vinho, mas sim de deixar que o ente seja como é, permitindo que se mostre em suas potencialidades, ainda que as mesmas pertençam mais ao que se julga inútil desde o olhar utilitarista que rege o estar no mundo. Assim, se bem a árvore não sirva aos propósitos da marcenaria, ela, ainda sim, permite que o ser humano aproveite de sua sombra "sem nada fazer", sem que isso demande a ação humana de modo a intervir em seu ser. Ou no caso da cabaça gigante que sendo como é, pode vir a convocar o humano para que ela mesma se torne uma espécie de embarcação. O mesmo respeito ao unguento, quer dizer, da cura da seda ao triunfo do rei, o que entra em jogo é algo que lhe pertence propriamente. É significativo que todos os exemplos demarcam algo do pensamento taoísta incorporado pelo conceito do não agir (Wúwéi), que não significa um simples nada fazer, mas certa prudência e medida serena na lida para com as coisas.

A terceira menção de Heidegger ao Chuang Tzu, embora restrita a uma ementa ${ }^{27}$, colabora na reflexão até aqui apresentada. Heidegger se refere a ela como O campanário (Glockenspielständer). Trata-se da parábola do carpinteiro Qing e o seu campanário que chamava a atenção de todos por sua beleza, parecendo mais ter sido feita por um espírito ou um deus do que por um ser humano ${ }^{28}$. Quando interrogado sobre quais técnicas havia utilizado para alcançar tanta beleza, o carpinteiro respondia não possuir nenhuma, mas explicava que, após jejuar por vários dias, havia dominado sua mente e já não se encontrava nele nenhuma ideia de elogios e recompensas, técnicas ou habilidades condizentes com o que tinha que fazer. Simplesmente adentrou no bosque ensimesmado com sua arte e separado por completo da algazarra exterior e, examinando a natureza das árvores, descobriu a forma perfeita para suportar os sinos. O carpinteiro não impôs à matéria uma

\section{$26 \mathrm{Id}$.}

$27 \mathrm{O}$ seminário indicava também a leitura de outros textos: Confissões, Livro $\mathrm{X}$ de Agostinho de Hipona, um dístico em Da experiência do pensar, Sobre a arte moderna de Paul Klee e o Fragmento 112 de Heráclito. HEIDEGGER, M. "Bild und Wort", In Zum Wesen der Sprache und zur Frage nach der Kunst (1950). GA 74. Klostermann, Frankfurt an Main, 2010, p. 185.

28 ChUANG-TZu. Op. cit., pp. 194-195. 
forma adequada aos seus propósitos, senão que deixou que árvore se mostrasse como era, de tal forma que dentre as tantas possibilidades que poderiam conceder um sentido à árvore, uma não dependia propriamente do agir humano. Foi necessário um olhar despojado, o do carpinteiro, para que a árvore também se mostrasse como campanário, um olhar que é um deixar-ser.

Finalmente, A alegria dos peixes, um texto que, narra Petzet, é lido por Heidegger em um momento de confraternização e descontração em Bremen, após ter proferido A essência da verdade. Pouco mais se sabe desse momento, exceto que uma discussão acerca da possibilidade de alguém se colocar no lugar do outro para conhecer o que outro estaria a sentir, fez com que Heidegger convocasse as palavras de Chuang-tzu e o seu diálogo com Hui-tzu. Chuang-tzu afirma a alegria dos peixes e justifica sua afirmação pelo simples fato de passar pela ponte. Nesse lugar, em uma ponte -lugar tão caro a Heideggerdá-se uma reunião integradora que faz o mundo acontecer de tal forma que as coisas vigoram em seu próprio ser. Os peixes estão alegres porque habitam o livre. Chuang-tzu sabe deles e de sua alegria porque também ele habita o mesmo lugar.

A exposição das diversas menções que Heidegger faz do Chuang-tzu evidenciou que o interesse do alemão não se restringe a ser apenas um conhecimento entre outros. Mais que manifestar a erudição do filósofo, Chuang-tzu mostra-se como um pensador que com suas parábolas contribuiu na formação e explicitação do pensamento do alemão. Contribui em um sentido bem específico, uma vez que para Heidegger o pensamento, sempre vinculado ao inútil, exige um questionar. Apesar de distante, não só no tempo, mas também por uma língua e uma tradição não ocidentais, Chuang-tzu surge como um interlocutor capaz de trazer questões que correspondem às de Heidegger.

A necessária confrontação com o asiático é para Heidegger a possibilidade concreta do ser humano questionar a si mesmo, ao modo como habita o mundo e se relaciona com a natureza e de chegar a reconhecer que o seu destino, seja qual for, está marcado pela falta de um pensamento capaz de colocar em questão o que é digno de ser pensado. Ao fruto dessa confrontação nos referimos como "o cultivo do inútil". Por cultivo se entende a capacidade humana de cuidar e lograr espaços nos quais a sua intervenção e controle sejam minimamente requeridos, deixando as coisas livres para que sejam o que são. Nesse "deixar algo entregue à sua própria essência é que estamos verdadeiramente livres"29. Enquanto tal, cultivar quer dizer um permitir que as coisas cheguem a ser o que são, antes de se transformarem em objeto da especulação e do planejamento que

29 HeIDEGGER, M. "Abendgespräch in einem Kriegsgefangenenlager in Russland zwischen einem Jüngeren und einem Älteren". cit., p. 230. 
visam a instauração e a segurança do útil por toda parte. O cultivo, no entanto, não é um nada fazer no sentido de uma resignação frustrante e impotente. Mas a descoberta de que, de um modo ainda pouco esclarecido, o ser humano está chamado a contribuir na realização das coisas, deixando o ser ser. Enquanto um cultivo, o deixar-ser desperta o ser humano para seu próprio poder e o seu comprometimento com esse chamado. Se agora pensamos em um veleiro amarrado ao cais e consideramos a sua essência, reconhecemos que uma embarcação foi construída para navegar, seja para o transporte de carga ou de pessoas, para negócios ou lazer. É certo que na sua construção também se considerou a sua capacidade de fundear ou de permanecer preso ao cais, muitas vezes para sua própria preservação. A partir da compreensão do habitar regido pelo útil, o barco é um tipo de instrumento que assegura o transporte por rios e mares para diferentes fins. Sendo algo construído conforme uma configuração técnica, o barco deve corresponder e requerer uma comandância e um saber. Mas, o que acontece quando pensamos nesse barco desde a perspectiva do inútil? Seria uma tolice pensar que para deixar o barco ser o que é, bastaria com soltar as amarras e deixá-lo à deriva para que gozasse da liberdade do seu ser. O barco demanda um timoneiro comprometido com manejar de suas velas e estar atento ao rodar dos ventos para evitar os perigos de um naufrágio. Comprometer-se significa estar em uma relação de mútuo pertencimento, relação a partir da qual acontece de ser propriamente a navegação; o timoneiro cuida de que o barco seja sempre e a cada vez barco. Percebemos, então, vigorar um outro sentido, o do inútil, o do próprio pensamento. Agir pode não ser somente a compulsão e a ansiedade de produzir resultados que confirmem a ubiquidade de seu poder e seu querer, mas sim a possibilidade do ser humano habitar e construir seu mundo "na medida em que pensa". Pensar é agir em seu sentido mais essencial e libertador. "O pensamento seria, então o inútil"30.

O cultivo do inútil, como sentido que emerge do encontro de Heidegger com Chuangtzu tem como consequência um questionamento autêntico do mundo contemporâneo, a era da metafísica consumada. Do ponto de vista de uma concepção ambientalista radical, o cultivo do inútil permite ver a época que vivemos desde uma perspectiva inabitual e não-ocidental, permitindo pensar a desmedida e a fúria presentes na manipulação da terra e de tudo que nela tem lugar, promovendo uma ética ambiental de caráter Heideggerian-cum-Daoist ${ }^{31}$. O perigo imediato dessa manipulação, com as suas inúmeras e já cotidianas tragédias que assolam o nosso país e o mundo, pouco permite visualizar o verdadeiro perigo, a saber, o desterro do humano e o abandono do pensar. Nesse sentido, o cultivo do inútil é uma necessidade e uma possibilidade humana não só respeito a si

30 lb. p. 221.

31 RentMeester, C. Heidegger and the environment. Rowman \& Littlefield, Lanham, 2016, p. 97. 
mesmo, mas também respeito ao que compreendemos por natureza e ao modo como nos comportarmos junto a ela.

\section{Referências Bibliográficas.}

ChuAng-Tzu. Zhuang zi - Maestro Chuang Tsé. Tr. I. Preciado. Kairós, Barcelona, 1996.

ChuANG-Tzu. Zhuang zi jin zhu jin yi. Ed. Chen Guying. Shangwu, Taibei, 1977.

HeIDEgGeR, Martin. "Abendgespräch in einem Kriegsgefangenenlager in Russland zwischen einem Jüngeren und einem Älteren". In Feldweg-Spräche 1944/1945. GA 77. Klostermann, Franfurt an Main, 1995. Pp. 203-245.

HEIDEgGER, M. "Bild und Wort", In Zum Wesen der Sprache und zur Frage nach der Kunst (1950). GA 74. Klostermann, Frankfurt an Main, 2010.

HeIDEgGer, Martin. "Die Armut". In Zum Ereignis-Denken. GA 73-1. Klostermann, Frankfurt an Main, 2013. Pp.873-881 (La pobreza. Amorrortu, Buenos Aires-Madrid, 2006).

HeIDEgGeR, Martin. Einfuhrung in die Metaphysik. GA 40. Klostermann, Frankfurt an Main, 1983 (Introducción a la Metafísica. Tr. A. Ackerman. Gedisa, Barcelona, 2001).

HeIDEGgER, Martin. Überlieferte Sprache und technische Sprache. Erker, St. Gallen, 1989 (Língua de tradição e língua técnica. Tr. M. Botas. Passagens, Mafra, 1995).

HeIDEgGeR, Martin. Vorträge und Aufsätze. GA 7. Klostermann, Frankfurt an Main, 2000 (Conferencias y artículos. Tr. E. Barjau. Odós, Barcelona, 1994).

MAY, Reinhard. Heidegger's hidden sources - East asian influences on his work. Routledge, London-New York, 1996.

PETZET, Heinrich Wiegand. Encuentros y diálogos con Martin Heidegger 1929-1976. Tr. L. Langbehn. Katz, Buenos Aires, 2007.

RentMeester, Casey. Heidegger and the environment. Rowman \& Littlefield, Lanham, 2016.

SAviAnI, Carlo. El Oriente de Heidegger. Tr. R. Bouso. Herder, Barcelona, 2004. 